\title{
Journal of Blood Disorders \& Transfusion
}

\section{Lactate Dehydrogenase (LDH) as Prognostic Marker in Acute Leukemia "Quantitative Method"}

\section{Walaa Fikry Mohammed Elbossaty}

Department of Chemistry, Faculty of Science, Damietta University, Damietta, Egypt

*Corresponding author: Walaa Fikry Mohammed Elbossaty, Department of Chemistry, Biochemistry division, Faculty of science, Damietta University, Damietta, Box 34517, Egypt, Tel: 020573761683; E-mail: Walaafikry@ymail.com

Received: December 12, 2016; Accepted: January 28, 2017; Published: February 3, 2017

Copyright: ( 2017 Walaa Fikry ME. This is an open-access article distributed under the terms of the Creative Commons Attribution License, which permits unrestricted use, distribution, and reproduction in any medium, provided the original author and source are credited.

\section{Abstract}

Lactate dehydrogenase enzyme was found in animal and human and play important role in gluconeogenesis process. It distributed in all organs, but the mainly distributed in liver. To evaluated the level of lactate dehydrogenase (LDH) in acute leukemia and investigated its clinical significance with other hematological and clinical parameters. Serum lactate dehydrogenase (LDH) level was investigated in 50 patients with acute leukemia, 17 patients with acute lymphoblastic leukemia and 33 patients with acute myeloid leukemia, in addition to 20 healthy control cases. The relationship between lactate dehydrogenase level and blood cells were analyzed. LDH level was significant elevated in acute leukemia cases as compared to control group, also LDH level was statistically significant increase in acute lymphoblastic leukemia than in acute myeloid leukemia $(p<0.001)$. There were positively correlation between LDH and white blood cells, bone marrow blasts and uric acid; on the other hand, there were negatively correlation between LDH and red blood cells, and platelets. Lactate dehydrogenases represented as supplementary enzymatic tool can be used as differentiation marker between the different types of leukemia not only but also, follow up the patients during treatment period.
\end{abstract}

Keywords: Acute lymphoblastic leukemia; Acute myeloid leukemia; LDH; WBCs; PLT; RBCs

\section{Introduction}

Leukemia's classification has been based traditionally on morphological features which are often subject to personality's skills of the investigator. In the last years there were different methods for this such as cytochemical analysis, immunophenotyping and enzyme abnormalities have been used in the classification and subtyping of leukemic cells [1].

According to disturbances which occur in acute leukemia result from the cell destruction and over growth of up normal malignant cell. There was glycolytic enzymes lactate dehydrogenase (LDH), which it was distributed in all organs but, mainly found in liver and represent as necessary factor in gluconeogenesis process where it responsible for acceleration of convert pyruvate into lactate to which act as fuel for energy. Lactate dehydrogenase was gradually elevated in the cell damage. The plasma level of the lactate dehydrogenase has been studied extensively in patients with leukemia $[2,3]$.

There was a favorable relationship between tumor and increased serum lactate dehydrogenase (LDH) level. Lactate dehydrogenase level was elevated in acute leukemia cases depend on their cell type. Highly elevation in Lactate dehydrogenase was found in patients with acute lymphoblastic leukemia and related with increased cell proliferation and turnover [4]. It is thought that the determination of serum lactate dehydrogenase activity has received attention in several medical fields both as a diagnostic tool and as clinical laboratory procedures because of the promise that it has shown in the diagnosis and prognosis of childhood ALL [2].
Determination of serum lactate dehydrogenase represent as simple method for detection of cancer. Elevated of lactate dehydrogenase associated with leucocytosis and cytopenias. High level of LDH can caused relapse in ALL [4].

LDH level was correlated with the cell migration and tumor lysis [5]. Quantification of LDH can use as chemotherapy tools [6]. LDH correlated with cancer development and tumor burned [7].

As the estimation of serum lactate dehydrogenase is easy, readily available and economic, therefore, this study was conducted to evaluate that serum lactate dehydrogenase level in acute leukemia patients.

\section{Materials and Methods}

\section{Study subjects}

The study was included on 50 patients with acute leukemia at initial diagnosis in addition to 20 cases healthy control. The diagnosis of acute leukemia was determined according to criteria proposed by the French-American-British Cooperative Group. Acute leukemia patients were classified in to 2 groups, first group was acute lymphoblastic leukemia $(n=17)$ and the other group was acute myeloid leukemia group $(n=33)$. Experiments involving human subjects were conducted according to the Declaration of Helsinki: the study was approved by the Ethics Committee Mansoura University. All patients as well as healthy person enrollments were voluntary and with informed consent.

\section{Sample collection}

Blood samples were with drowned from all acute leukemia patients in addition to healthy cases, and then there were allowed to colt then centrifuged to obtain serum sample. Serum samples were isolated and 
stored until used at $2-8^{\circ} \mathrm{C}$ for up to 48 hours prior to assay or for prolonged storage aliquot and kept at $-20^{\circ} \mathrm{C}$.

\section{Enzymes Assay}

Serum lactate dehydrogenase was detected according to the Morgenstern's method [8] determination of the lactate dehydrogenase activity optimized the test according to the recommendation of SFBC (Societe Francaise de biologic Clinique)

\section{Pyruvate $+\mathrm{NADH}+\mathrm{H}+\mathrm{LDH} \rightarrow$ Lactate $+\mathrm{NAD}+$}

The activity of LDH is shown by the variation of optical density at $340 \mathrm{~nm}$ this is proportional to the quantity of NADH oxidized.

One millilire of working reagent was pipetted in cuvette. After that $20 \mu \mathrm{l}$ of serum sample was added. Shake well and wait, for $1 \mathrm{~min}$. Measure the extinction decrease per min.

\section{Calculation}

$\Delta \mathrm{OD} / \mathrm{mn} \times 8095=\mathrm{IU} / \mathrm{L}$

The concentration of standard=8095 U/L (Unit per litre).

Enzyme activity is expressed in international units (IU), which is equivalent to the amount of enzyme that catalyzes the conversion of 1 $\mu$ mole of substrate per minute [9].

\section{Hematological parameters}

All patients subjected to detailed history taking and clinical examinations. Hematological parameters were detected by fully automated 5 part cell counter (SYSMEX XT 2000-I). Peripheral smear examination was done to find out the presence of leukemic blasts. Bone marrow aspiration was performed from right iliac crest under strict asepsis with $5 \mathrm{ml}$ of $2 \%$ xylocaine infiltration anesthesia. Smears were analyzed by staining with Leishman stain and Myeloperoxidase (MPO).

\section{Determination of serum uric acid}

Uric acid and its salts are end products of the purine metabolism. Uric acid is oxidized by uricase to allantoine and hydrogen peroxide $\left(2 \mathrm{H}_{2} \mathrm{O}_{2}\right)$, which under the influence of peroxidase (POD), 4aminophenazone (4-AP) and 2-4 Dichlorophenol sulfonate (DCPS) forms a red quinoneimine compound [10].

Uric acid $+2 \mathrm{H}_{2} \mathrm{O}+\mathrm{O}_{2} \rightarrow$ Uricase $\rightarrow$ Allantoine $+\mathrm{CO}_{2}+2 \mathrm{H}_{2} \mathrm{O}_{2}$

$2 \mathrm{H}_{2} \mathrm{O}_{2}+4-\mathrm{AP}+$ DCPS $\rightarrow$ Quinoneimine $+4 \mathrm{H}_{2} \mathrm{O}$

The intensity of the red color formed is proportional to the uric acid concentration in the sample. One millilitre of working reagent was pipetted in cuvette. After that $25 \mu \mathrm{L}$ of serum sample was added. Mixed and incubated for $5 \mathrm{~min}$ at $37^{\circ} \mathrm{C}$ or $10 \mathrm{~min}$ at $15-25^{\circ} \mathrm{C}$. The absorbance (A) of the samples and Standard were read against the Blank.

\section{Calculations}

Serum or plasma (A) Sample/(A) Standard $\times 6$ (Standard concentration $)=\mathrm{mg} / \mathrm{dL}$ uric acid in the sample.

\section{Statistical analysis}

Quantitative data were presented as mean and standard deviation or median and range. The quantitative data were examined by Kolmogrov Smirnov test for normality. For comparison between two groups; student t-test test (for non-parametric data) was used. For comparison between more than two groups; one way ANOVA test (for nonparametric data) was used. The spearman correlation coefficient $(r)$ was used for measuring the relationship between two variables. Kaplan-Meier test was used for survival analysis and the statistical significance of differences among curves was determined by Log-Rank test. The predict probability of being diagnosed with AML and ALL was used as a surrogate marker to construct receiver operating characteristic (ROC) curve. Area under the ROC curve (AUC) was used as an accuracy index for evaluating the diagnostic performance of Lactate dehydrogenase.

Statistical analysis was performed using SPSS version 17 (SPSS Inc., Chicago, IL, USA). Significance was set at $\mathrm{p}<0.05$.

\section{Results}

The result of this study were summarized in (Tables 1-4) and (Figures 1 to 8 ).

\section{Clinical features}

The clinical features of the patients and healthy control were shown in (Figure 1). There were 17 patients with ALL ( 9 cases were male and 7 were female, (Mean age $34.4 \pm 14.1$ ), 33 patients with AML (25 case were male and 8 case were female), (Mean age $43.3 \pm 13.9)$ and 20 healthy control cases (10 cases were male and 10 were female). All cases were characterized in to four groups according to age. The higher number of ALL cases was found in 25-40 group, while the higher number of AML cases was appeared in 40-55 group.

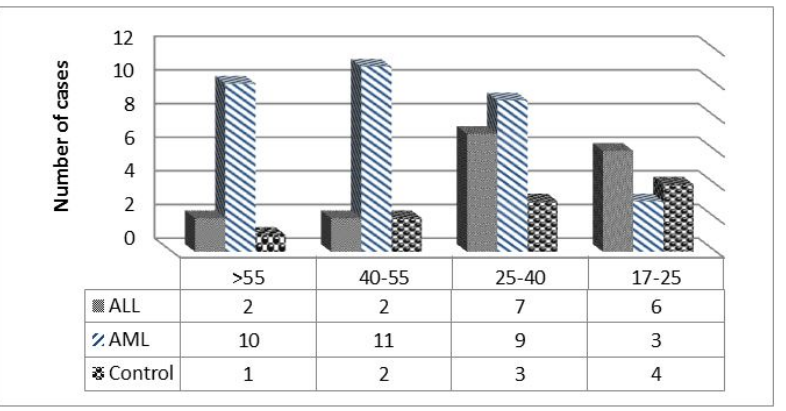

Figure 1: Age groups distribution between different studied groups.

\section{Biochemical analysis of LDH in all studied groups}

There was statistically significant increase in Lactate dehydrogenase activity in acute leukemia cases in compared to healthy control $(\mathrm{p}<0.0001)$.

Also, lactate dehydrogenase activity was highly significant in acute lymphoblastic leukemia as compared to acute myeloid leukemia $(\mathrm{p}<0.0001)$. The levels of serum LDH of the patients with leukemia and healthy control were summarized in (Table 1) and (Figure 2). 
Citation: Walaa Fikry ME (2017) Lactate Dehydrogenase (LDH) as Prognostic Marker in Acute Leukemia "Quantitative Method". J Blood Disord Transfus 8: 375. doi:10.4172/2155-9864.1000375

Page 3 of 7

\begin{tabular}{|c|c|c|c|c|c|c|}
\hline \multirow{2}{*}{ Diagnosis } & \multirow{2}{*}{$\mathbf{N}$} & \multicolumn{2}{|c|}{ LDH (IU/L) } & \multirow[t]{2}{*}{ P1 } & \multirow{2}{*}{ P2 } & \multirow{2}{*}{ P3 } \\
\hline & & Mean \pm SD & Range & & & \\
\hline Control & 20 & $96.5 \pm 44.2$ & 78-143 & \multirow{3}{*}{$<0.001^{* *} \boldsymbol{\Delta}$} & \multirow{3}{*}{$<0.001^{* \star} \boldsymbol{\Lambda}$} & \multirow{3}{*}{$<0.001^{* *} \boldsymbol{\Delta}$} \\
\hline AML & 33 & $569.7 \pm 340.2$ & $192-3524$ & & & \\
\hline ALL & 17 & $1744 \pm 1040$ & $234-4274$ & & & \\
\hline
\end{tabular}

Table 1: Lactate dehydrogenase activity in different studied groups P1: comparison between AML versus control; P2: comparison between ALL versus control; P3: comparison between ALL versus AML; ${ }^{* *}: \mathrm{P}=<0.001$ highly Significant; Mean \pm SD: Mean \pm Standard Deviation.

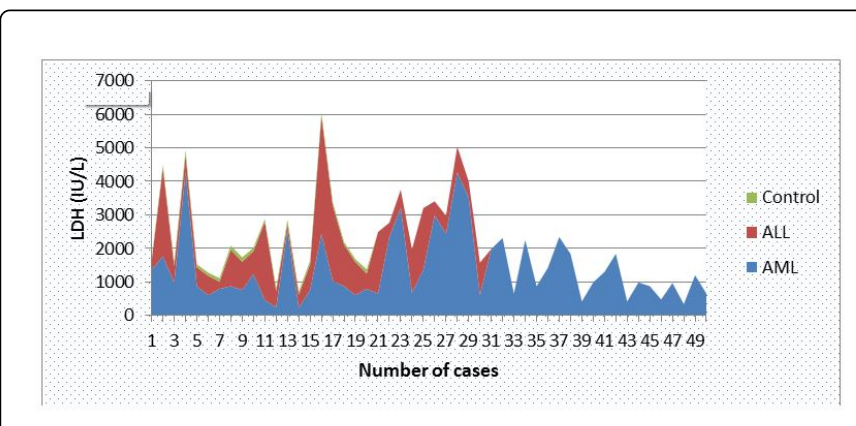

Figure 2: Distribution of lactate dehydrogenase activity between studied cases.

\section{Relation between Lactate dehydrogenase activity and age}

Figure 3 show the variation in serum LDH levels in leukemic patients with respect to the different age groups. In the age group between $17-25$ to $40-55$ years, there was increase in the mean LDH levels in ALL patients (880.77 \pm 214.12 to $2367.5 \pm 758.4$ ), whereas in age group $>55$ there is decline in the mean LDH levels $(520 \pm 321.4)$. In age group between $17-25$ years to $40-55$ years there was gradually increase in the mean LDH level $(423.6 \pm 514.8$ to $1048.95 \pm 758.4)$ and with increasing in age as in group $>55$ years there was decrease in the mean LDH level (668.12 \pm 206.9 years) in AML.

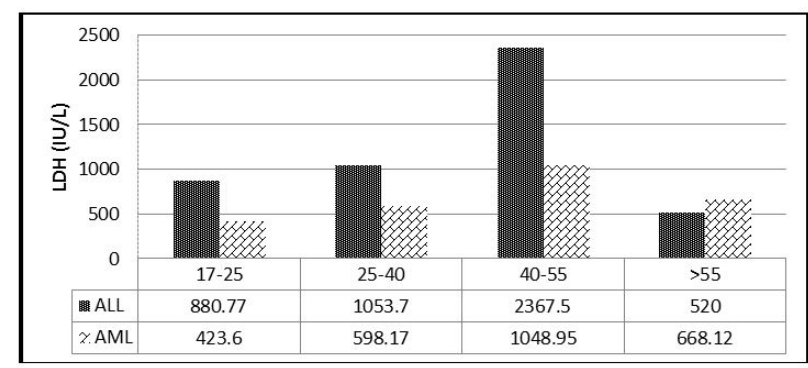

Figure 3: Distribution of lactate dehydrogenase between age groups.

\section{Distribution of Lactate dehydrogenase according to gender}

In this study LDH levels were different distributed in depend on the type of gender, where a female shows higher levels of enzyme activity as compared to males. (Table 2) was shown the variation in Lactate dehydrogenase activity in respect to gender, the mean lactate dehydrogenase levels in males $(1601.8 \pm 1641.25)$ were found to be more than that in females $(900.8 \pm 407.51)$ in ALL, while in AML, the mean lactate dehydrogenase levels in males $(1318.1 \pm 669.51)$ were found to be more than that in females $(644.3 \pm 488.64)$.

\begin{tabular}{|l|l|l|}
\hline Gender & ALL & AML \\
\hline Male & $1601.8 \boldsymbol{\Lambda}$ & $1318.1 \mathbf{\Lambda}$ \\
\hline Female & 900.8 & 644.3 \\
\hline TEST STATISTICS & 7.08 & 9.08 \\
\hline Student $-\mathrm{t}$ test & $<0.0001^{* * *}$ & $<0.0001^{* * *}$ \\
\hline
\end{tabular}

Table 2: Distribution of lactate dehydrogenase according to gender.

\begin{tabular}{|l|l|l|l|}
\hline $\begin{array}{l}\text { Immunological } \\
\text { Subtype }\end{array}$ & $\mathbf{N}$ & $\%$ & $\begin{array}{l}\text { LDH (IU/L) } \\
\text { Mean } \pm \text { SD } \\
\text { (Range) }\end{array}$ \\
\hline T-ALL & 5 & 29.4 & $2000 \pm 1456.6(654-2274)$ \\
\hline B-ALL & 12 & 70.6 & $1424.5 \pm 1122.5(234-2274)$ \\
\hline TEST STATISTICS & 2 & 6.1 & $\begin{array}{l}\text { F= 0.98 } \\
0.55\end{array}$ \\
\hline M0 & 6 & 18.2 & $721.5 \pm 375.5(456-987)$ \\
\hline M1 & 7 & 21.2 & $1149 \pm 862.4(488-2250)$ \\
\hline M2 & 9 & 27.3 & $1311.9 \pm 761.8(341-2635)$ \\
\hline M4 & 5 & 15.2 & $572.9 \pm 295.7(212-987)$ \\
\hline M5 & 3 & 9 & $1070 \pm 749.4(421-2312)$ \\
\hline M6 & 1 & 3 & $306.5 \pm 161.5(192-421)$ \\
\hline M7 & & $\begin{array}{l}\text { F=2.28 } \\
0.038^{*}\end{array}$ \\
\hline TEST STATISTICS & & \\
\hline
\end{tabular}

Table 3: Correlation of intracellular enzyme activities of LDH and morphological subtypes in acute leukemia. 
Citation: Walaa Fikry ME (2017) Lactate Dehydrogenase (LDH) as Prognostic Marker in Acute Leukemia "Quantitative Method". J Blood Disord

Page 4 of 7

\section{Lactate dehydrogenase activity and immunological subtypes of acute leukemia}

Lactate dehydrogenase distributed in different subtypes of acute leukemia according to FAB classification was shown in (Table 3), where the higher median in lactate dehydrogenase was shown T-ALL (719.32) as compared to (639.9) in B-ALL. In AML, the higher median in lactate dehydrogenase was shown AML-M2 (478.01), and the low value was shown in AML-M7 (191.9).

\section{Clinical and hematological parameters in all studied groups}

Figure 4 shows the clinical and hematological parameters variation between different studied groups, where there was statistically significant increase in white blood cell, uric acid and bone marrow blasts count in both acute lymphoblastic leukemia and acute myeloid leukemia patients as compared to control. While, there were statistically significant decrease in red blood cells and platelets count in both acute lymphoblastic leukemia and acute myeloid leukemia patients as compared to control. As well as, the ratio between lactate dehydrogenase to uric acid, white blood cells, red blood cells, platelets and bone marrow blasts were highly increase in acute lymphoblastic leukemia then acute myeloid leukemia as compared to control.

\section{Hematological and clinical parameters according to lactate dehydrogenase activity}

According to the activity of lactated dehydrogenase we classified acute leukemia patients in to two groups, one group in which lactate dehydrogenase activity $>350 \mathrm{IU} / \mathrm{L}$ (High Lactate dehydrogenase activity group) and the other group in which lactate dehydrogenase activity $<350 \mathrm{IU} / \mathrm{L}$ (Low Lactate dehydrogenase activity group). In this study, elevated of Lactate dehydrogenase activity accompanied with increasing of white blood cells, bone marrow blasts and uric acid. On the other hand, depression in Lactate dehydrogenase activity accompanied with increasing of red blood cells and Platelets (Table 4).

\begin{tabular}{|l|l|l|l|}
\hline \multirow{2}{*}{ Parameters } & High lactate dehydrogenase activity & Low lactate dehydrogenase activity & $\mathbf{p}$ \\
\cline { 2 - 4 } & Mean \pm SD & Mean \pm SD & $<0.0001^{* * *}$ \\
\hline White blood cells (109/L) & $45.29 \pm 53.7$ & $23.8 \pm 16.4$ & 0.9 \\
\hline Red blood cells (109/L) & $3.2 \pm 0.76$ & $3.29 \pm 1.2$ & $0.02^{*}$ \\
\hline Platelets (109/L) & $64.6 \pm 56.5$ & $134.25 \pm 124.8$ & 0.74 \\
\hline Bone marrow blasts (\%) & $73.83 \pm 15.38$ & $68.83 \pm 27.2$ & $<0.0001^{* * *}$ \\
\hline Uric acid (mg/L) & $7.35 \pm 4.01$ & $4.93 \pm 1.2$ & \\
\hline
\end{tabular}

Table 4: Comparison of hematological and clinical data according to Lactate dehydrogenase activity in acute leukemia patients.

\section{Correlation between hematological and clinical parameters and lactate dehydrogenase activity}

Figures $5 \mathrm{a}-5 \mathrm{e}$ show there were positive significant correlation between lactate dehydrogenase activity and white blood cells, bone marrow blasts and uric acid. While there were negative significant correlation between lactate dehydrogenase activity and red blood cells and platelets.

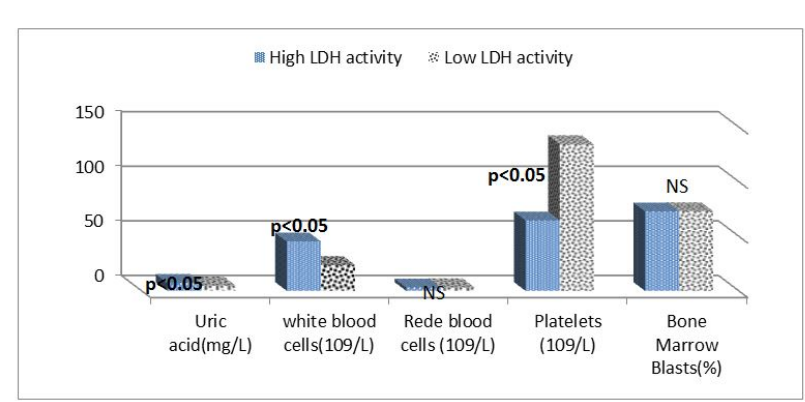

Figure 4: Hematological and clinical data according to Lactate dehydrogenase activity in acute leukemia patients.

\section{Clinical outcome according to Lactate dehydrogenase activity}

Figure 6 show comparison of outcome according to Lactate dehydrogenase activity in studied AML and ALL patients.
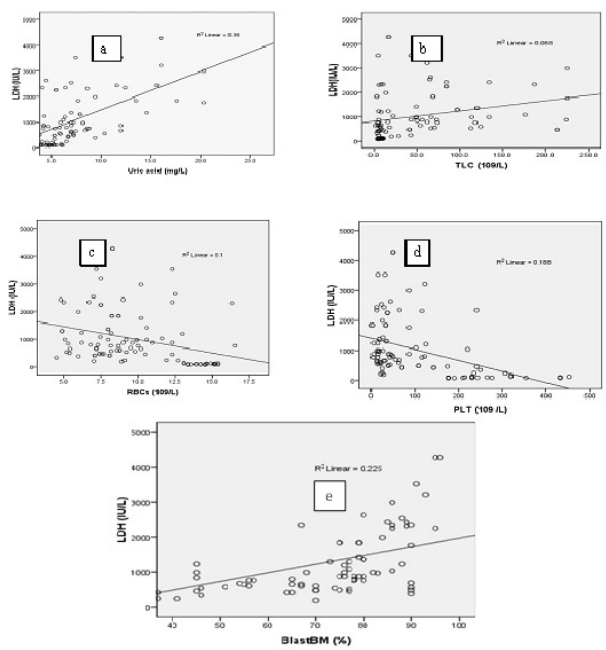

Figure 5: The correlation between lactate dehydrogenase activity and white blood cells, bone marrow blasts and uric acid 
Patients who expressed low LDH level achieved CR at significantly higher rates in AML and ALL, while those who expressed high LDH level achieved relapse at significantly higher rates in AML and ALL, and had significantly higher frequency for death in AL patients.

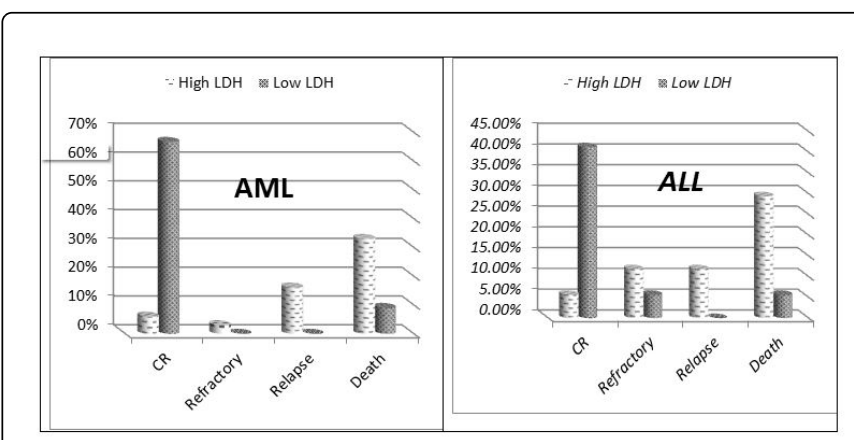

Figure 6: Clinical outcome according to lactate dehydrogenase activity in acute leukemia patients

\section{Survival times according to Lactate dehydrogenase activity in acute leukemia cases}

Kaplan-Meier analysis showed that the survival of patients with low lactate dehydrogenase activity was significantly longer than for patients with high activity

Figure $7 \mathrm{a}-7 \mathrm{~d}$ show relation between survival times according to Lactate dehydrogenase activity in acute leukemia patients. OS was significantly longer in patients who expressed lactate dehydrogenase below 350 (IU/L) in both AML and ALL groups when compared with patients who expressed lactate dehydrogenase above 350 (IU/L) which have shorter OS in both AML and ALL.

Also, DFS was non statistically significantly shorter in patients who expressed high lactate dehydrogenase in both AML and ALL groups when compared with patients who expressed low lactate dehydrogenase which have longer DFS in both AML and ALL.

\section{Lactate dehydrogenase sensitivity and specificity analysis}

ROC curve analysis was shown in Figure 8a-8e. Lactate dehydrogenase act as a diagnostic test for acute leukemia; the sensitivity and specificity of LDH were $(92.5 \%$ and $100 \%)$ respectively. The area under the receiver operating characteristic (ROC) curve for Lactate dehydrogenase was 0.834 .

\section{Discussion}

Leukemia's are a heterogeneous disease in which there were different in genetic abnormalities which play important role in growth and death [11]. There were different technique for detection and differentiate acute leukemia, but this methods may less available, not specific and expensive. In this study we try to choose simple and cheap technique to diagnosis and differentiate acute leukemia. Lactate dehydrogenase act as glycolytic enzyme increase in malignant cell than in normal cell. Malignant cells have a special kind of metabolism in depend on glycolytic sequence and Krebs cycle to obtain its own fuel of energy, so the cells move to exhausted glucose from five to ten times more than normal cells, to convert it to lactate [12].

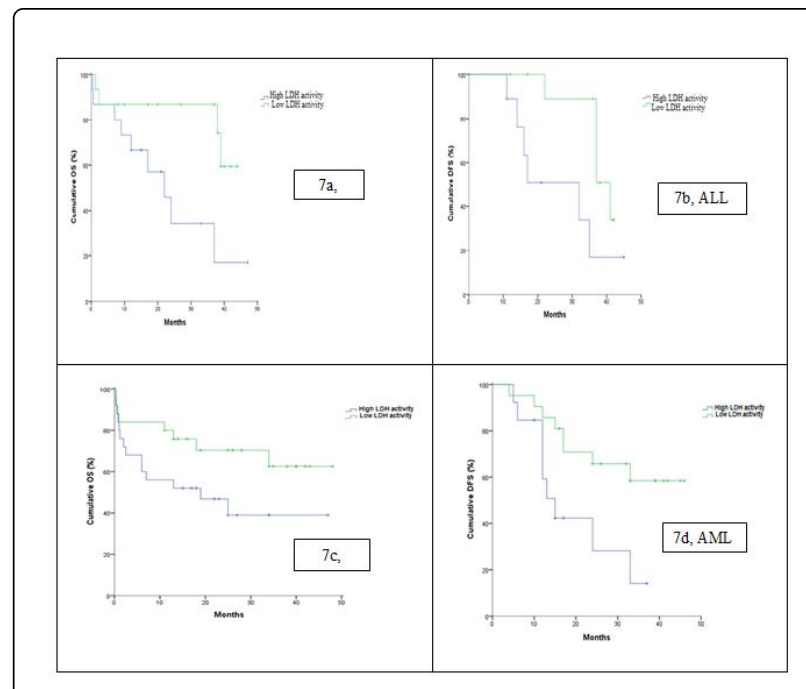

Figure 7: The relation between survival times according to lactate dehydrogenase activity in acute leukemia patients.

Under rapid proliferation and immaturity of tumor cells, LDH is released due to multiple cytokine activity and cell membrane damage [13]. Any change in lactate dehydrogenase level in blood is a reflection for the presence of cell damage. This change may be due to an altered amount of the enzyme forming tissue, as defect in rate of enzyme synthesis, or due to defect in the permeability of the cell member as a result of physiological stress.

In acute leukemia level of lactate dehydrogenase elevated due to the cell destruction and tumor turnover. Elevated $\mathrm{LDH}$ is unfavorable prognostic factor for several malignancies, including acute leukemia.

There were many possible mechanisms which explain the reason of elevated of lactate dehydrogenase in malignancy tumor. First, acidification of the extracellular water space by lactate and the subsequent activation of tumor invasion may be a rational explanation [14]. Second, low $\mathrm{pH}$ microenvironment may increase cancer cell resistance to hypoxia-induced apoptosis by protecting mitochondria from oxidative stress [15]. Finally overexpression of $\mathrm{LDH}$, especially LDH5, reflects an up regulated hypoxia-induced factor pathway, which regulates glycolysis, angiogenesis, resistance to apoptosis, and even cancer metastasis [16].

Although difficulty in counting leukemic tumor burden by tumor size or number of tumor cells, Lactate dehydrogenase was viewed as a simple biochemical marker for leukemic tumor burden prediction. Furthermore, Vidriales et al. [17] showed that serum LDH level was proportional to leukemic cells in synthetic phase.

This study was planned to investigate the role of lactate dehydrogenase as prognostic marker for acute leukemia, also, in differentiation between different acute leukemia subtypes. In addition to its significance correlation with other clinical and hematological parameters. In the present study, both ALL and AML patients have higher statistically significant serum LDH levels than the control group. Elevation of serum LDH in acute leukemia patients may be due to the tumor burden activity which reflects the function of leukemic cell number and turnover. 


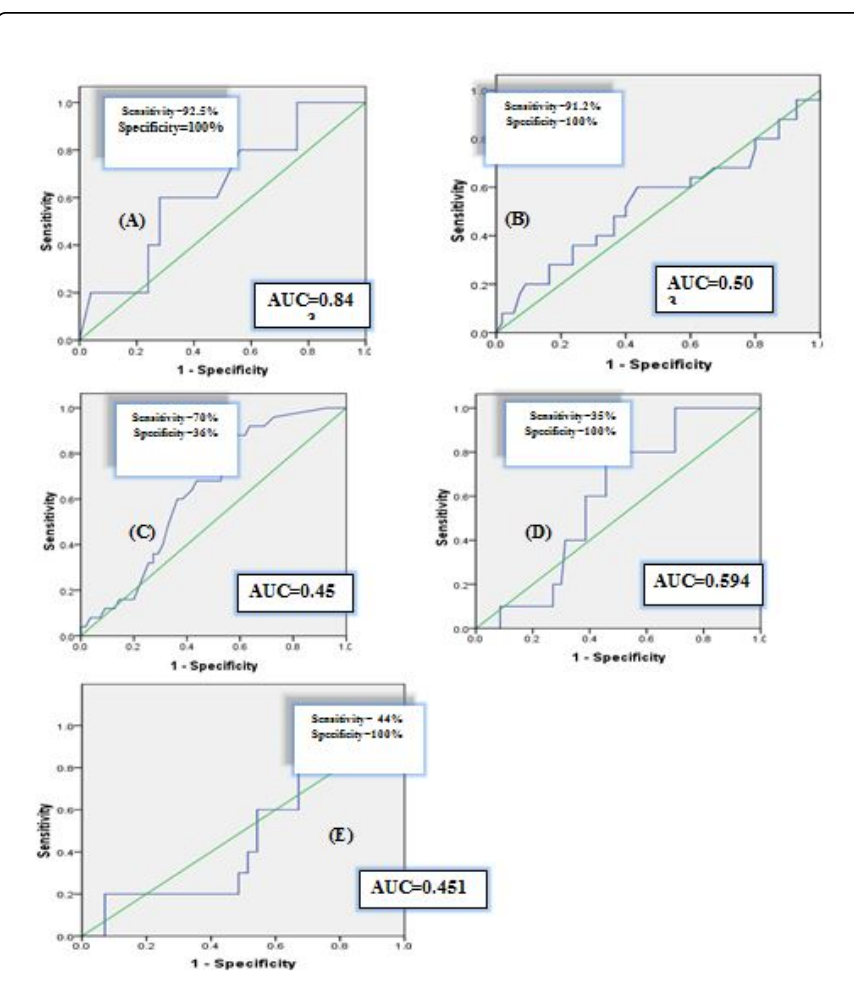

Figure 8: ROC curves showing sensitivity and specificity for (A) Lactate dehydrogenase, (B) Platelets, (C) Bone marrow blasts, (D) Uric acid and (E) White blood cells. ROC: receiver operating characteristic.

In this study lactate dehydrogenase activity was highly statistically significant in acute lymphoblastic leukemia than in acute myeloid leukemia. This difference may be due to there was difference in rate of glycolysis aerobic. This in coincided with Kornberg and Polliack study's [4], in which the lactate dehydrogenase level was significantly higher in patients with acute lymphatic leukemia (ALL) than in patients with acute myelocytic leukemia (AML).

The activity of lactate dehydrogenase increase in male more than in female in acute leukemia cases. The mean value of LDH is high in male when compared with the female this may be due to the sexual hormones. Estrogen regulates and has a negative correlation with LDH activity and so the value of female is less than the male. Estrogen hold a hydroxyl group on its steroid ring, its structure is similar to that of the antioxidant vitamin $\mathrm{E}$ and it donates its hydrogen ion from this hydroxyl group and scavenges the free radical and thus acts as antioxidant, estrogen has a protective effect on factors induced muscle damage in females as antioxidant, membrane stabilizer and influences neutrophil infiltration. The other cause may be the muscle fibers cross sectional area that is high in male than females which reflects the high LDH level in male than females [9].

There was good correlation between lactate dehydrogenase activity in respect to age, where its activity increase with increase of age until 55 years, then it's began to decrease in acute leukemia patients after that. This may be due to the activity of the disease and the rate of cell turnover. This agree with Pujari et al. [18], who reported that in respect to sex, the mean lactate dehydrogenase levels in females (1722.4 \pm 1557.9) were found to be more than that in males (1393.5 \pm 1197.6$)$.
However, we found a significant difference only in patients with chronic myeloid leukemia; whereas in respect to age, the mean lactate dehydrogenase levels were found to be elevated in 11-20 years (1935.9 $\pm 1684.2)$ and lowered in age group greater than 51 years (1288.9 \pm 1214.3). We observed highly significant $(\mathrm{p}<0.001)$ lactate dehydrogenase levels in all types of leukemia with respect to age.

There was difference in lactate dehydrogenase activity and FAB classification, this reflect that each type of leukemic cells have its own pathway in aerobic glycolysis according to their morphological feature. This in agreement with Anthony's study [19], who decided that there was correlation between lactate dehydrogenase activity and acute leukemia subtypes.

In this study, there were highly statistically significant increase in white blood cells, bone marrow blasts and uric acid in acute leukemia cases as compared to healthy control.

On the other hand, there were statistically significant decrease in red blood cells and platelets in acute leukemia cases as compared to healthy control. The ratio between lactate dehydrogenase activity and clinical parameters increase in acute leukemia patients than in healthy control, in spite of increase in acute lymphoblastic leukemia than in acute myeloid leukemia.

High lactate dehydrogenase activity was highly correlated with increase white blood cells, uric acid and bone marrow blasts this agree with one study in which higher serum LDH level was associated with higher leukocytes counts, lower blast cell DNA indices, lower platelet count and a larger spleen size [20].

Emad et al. [21], who found that high LDH levels in acute lymphoblastic leukemia (ALL) correlated with leukocyte counts and blast cells that were statistically significant $(\mathrm{P}<0.04$, and 0.001 respectively).

In this study, there were negatively correlation between lactate dehydrogenase activity and platelets and red blood cells, this in coincided with Wang Jing's study [22], who reported that there were negative correlation between lactate dehydrogenase activity and red blood cells and platelets.

Lactate dehydrogenase activity and uric acid levels may be elevated due to rapid cell turnover; this can lead to acute renal failure. Yamauchi et al. [23], who reported that Uric acid in serum (S-UA) is produced by the breakdown of the cellular nucleic acids of leukemia cells and may be a marker of disease aggressiveness.

Lactate dehydrogenase is a valuable prognostic marker in acute leukemia; patients can be classified in to different treatment protocols according to LDH activity [24].

High lactate dehydrogenase activity was correlated with chemotherapy resistance, less sensitivity to drug, hence short overall survival period and shorter disease free survival period as compared to low lactate dehydrogenase activity group [25].

On the basis of our study, we conclude that a high LDH level is an important independent predictor of poor survival for acute leukemia.

We evaluated the prognostic ability of Lactate dehydrogenase for discriminating patients with acute leukemia from healthy controls, and ROC curves of white blood cells, platelets, bone marrow blasts, uric acid and LDH were drawn.

The AUC for white blood cells, platelets, bone marrow blasts, uric acid and LDH was $0.451,0.503,0.459,0.594$ and 0.843 , respectively. In 
this study, LDH and platelets showed better sensitivity and specificity for the diagnosis of patients with acute leukemia compared with white blood cells, bone marrow blasts and uric acid [26].

In particular, Lactate dehydrogenase displayed the best prognostic ability. Enzymes have become the major choice in the medical field this is due to their high specificity and sensitivity. In this study lactate dehydrogenase has high sensitivity value $(92.5 \%)$ an addition to high specificity for acute leukemia (100\%).

Thus lactate dehydrogenase activity might be a useful addition to routine morphologic and cytochemical methods for diagnosis and classification of acute leukemia. Detection of lactate dehydrogenase activity was comparatively easy to perform due to its availability and price. Lactate dehydrogenase activity could be used as diagnostic tool in follow up the acute leukemia patients during their treatment.

\section{Conclusion}

Elevation of Lactate dehydrogenase activity in acute leukemia patients was reflecting the increase rate of aerobic glycolysis. Lactate dehydrogenase can be used as independent prognostic marker not only in diagnosis of acute leukemia but also, in classification of acute leukemia.

\section{Conflict of Interest}

The authors declare no conflict of interest.

\section{References}

1. Gralnick H, Galton A, Catovsky D, Sultan C, Bennet J (1977) Classification of acute leukemia. Ann Intern Med 87: 740-753.

2. Erickson R, Morales D (1961) Clinical use of lactic dehydrogenase. New Engl J Med 265: 478-482.

3. Pui C, Dodge R, Dahl G, Rivera G, Look A, et al. (1985) Serum lactic dehydrogenase level has prognostic value in childhood acute lymphoblast leukemia. Blood 66: 778-782.

4. Kornberg A, Polliack A (1980) Serum lactic dehydrogenase levels in acute leukemia: Marked elevations in lymphoblast leukemia. Blood 56: 351-355.

5. Magrath I, Lee YJ, Anderson T, Henle W, Ziegler J, et al. (1980) Prognostic factors in Burkitt's lymphoma. Cancer 45: 1507-1515.

6. Brindley C, Francis F (1963) Serum lactic dehydrogenase and glutamic oxaloacetic transaminase correlations with measurements of tumor masses during therapy. Cancer 23: 112-117.

7. Arseneau J, Canellos G, Banks P, Berard C, Gralnick H, et al. (1975) American Burkitt's lymphoma: A clinic pathologic study of 30 cases. American J Med 58: 314-321.

8. Morgenstern, Flor R, Kessler G, Klein B (1965) Automatized determination of NAD-coupled enzymes, determination of lactic dehydrogenase. Anal Biochem 13: 149-161.
9. Srividhya S, Pralay M, Subramanian A (2015) Reference interval for enzyme lactate dehydrogenase in male and female athletes. IJSR 6: 2319-7064.

10. Burtis A (1999) Tietz Textbook of Clinical Chemistry. 3rd ed AACC.

11. Walaa FE, Camelia A, Malak A, Doaa M (2015) Implications prognostic of clinic pathologic features in acute leukemia. World Journal of Pharmacy and Pharmaceutical Sciences 4: 413-428.

12. Flanagan N, Ridwny J, Platt C, Rowlands A, Whitson A (1989) Lactate dehydrogenase estimation in hematological malignancies. Clin Lab Haematol 11: 17-26.

13. Field M, Block J, Levin R (1966) Significance of blood lactate elevation among patients with acute leukemia and other lymphobastic proliferative disorder. American J Med 40: 528-547.

14. Stubbs M, McSheehy P, Griffiths J, Bashford C (2000) Causes and consequences of tumour acidity and implications for treatment. Mol Med Today 6: 15-19.

15. Bronk SF, Gores GJ (1991) Acidosis protects against lethal oxidative injury of liver sinusoidal endothelial cells. Hepatology 14: 150-157.

16. Semenza GL, Jiang BH, Leung SW, Passantino R, Concordet JP, et al. (1996) Hypoxia response elements in the aldolase A, enolase 1, and lactate dehydrogenase A gene promoters contain essential binding sites for hypoxia-inducible factor 1. J Biol Chem 271: 32529-32537.

17. Vidriales MB, Orfao A, Lopez-Berges MC, Gonzalez M, Lopez-Macedo A, et al. (1995) Prognostic value of S-phase cells in AML patients. Br J Haematol 89: 342-348.

18. Pujari S, Jadkar SP, Belwalkar GJ (1980) Lactate dehydrogenase levels in leukemia. Int J Pharma Bio Sci 3: B454-B459.

19. Anthony DH, Walter F, Werner H (1984) Plasma and intracehular levels of lactate dehydrogenase, phosphohexose isomerase and lysozyme activity in acute leukemia. Blut 49: 19-28.

20. Golam H, Mannan (2007) Serum lactate dehydrogenase level in childhood acute lymphoblastic leukemia. Bangladesh Med Res Counc Bull 33: 88-91.

21. Emad A Al-Saadoon, Lamia M Al-Naama, Janan KH (2003) Serum lactate dehydrogenase ( $\mathrm{LDH})$ activity in children with malignant diseases. Bahrain Medical Bulletin 25: 1-7.

22. Wang Jing, Chen Yi-Jue, Gu Ping, Fu Qt-hua (2011) Changes of trace elements and nutritional proteins in children with acute leukemia at remission stage. Chinese Journal of Clinical Nutrition 19: 84-87.

23. Yamauchi T, Negoro E, Lee S, Takai M, Matsuda Y, et al. (2013) A high serum uric acid level is associated with poor prognosis in patients with acute myeloid leukemia. Anticancer Res 33: 3947-3951.

24. Schwartz M (1992) Enzymes as prognostic markers and therapeutic indicators in patients with cancer. Clini Chim Acta 206: 77-84.

25. Kalaycio L, Rybicki B, Pohlman R, Dean J, Sweetenham S, et al. (2007) Elevated lactate dehydrogenase is an adverse predictor of outcome in HLA-matched sibling bone marrow transplant for acute myelogenous leukemia. Bone Marrow Transplant 40: 753-758.

26. Wolf P (1990) Clinical significance of an increased or decreased serum alkaline phosphates level. Arch Pathol Lab Med 102: 497-501. 